\title{
Evaluation of complication during third stage of labour at tertiary care center
}

\author{
Komal K. Rangholiya*, Saumya P. Agrawal, Sapana R. Shah, Hetal Dodiya
}

Department of Obstetrics and Gynecology, Sardar Vallabh Bhai Hospital, Ahmedabad, Gujarat, India

Received: 19 March 2020

Accepted: 22 April 2020

\section{*Correspondence:}

Dr. Komal K. Rangholiya,

E-mail: rangholiyakoma125121993@gmail.com

Copyright: (C) the author(s), publisher and licensee Medip Academy. This is an open-access article distributed under the terms of the Creative Commons Attribution Non-Commercial License, which permits unrestricted non-commercial use, distribution, and reproduction in any medium, provided the original work is properly cited.

\begin{abstract}
Background: The objective of the present study was to determine the maternal outcome of complications of third stage of labour and to determine the risk factors and evaluate the management protocols for these complications.

Methods: This is retrospective study of maternal outcome with complications of third stage of labour carried out at tertiary care centre from June 2016 to December 2019. Patients who developed any complications of third stage of labour after vaginal delivery or caesarean section were included.

Results: Complications observed during third stage of labour were atonic PPH $0.82 \%$ (74 cases), traumatic PPH $0.55 \%$ (50 cases), retained placenta (including placenta accreta spectrum) $0.21 \%$ (19 cases), secondary PPH $0.03 \%$ (3 cases), uterine inversion $0.03 \%$ ( 3 cases) and amniotic fluid embolism $0.01 \%$ ( 1 case). Maximum cases were seen in 18-24 years of age group. Only 36\% patients having atonic PPH responded to medical treatment, $46 \%$ patients having atonic PPH responded to conservative surgery, $18 \%$ of patients required radical surgery.

Conclusions: Third stage complications are potentially life threatening. Associated conditions for third stage complication are high parity, anemia, hydramnios, multiple pregnancy, malpresentation, placenta previa, and adherent placenta. Early anticipation and early intervention with proper planning is required to reduce the maternal morbidity and mortality in third stage complication.
\end{abstract}

Keywords: Postpartum haemorrhage, Perineal tears, Third stage complications, Traumatic postpartum haemorrhage

\section{INTRODUCTION}

The third stage of labour starts after expulsion of foetus and continues till expulsion of placenta. It can be sub categorized as phase of separation and phase of expulsion of placenta. The average time of third stage is $15 \mathrm{~min}$.

\section{The following are the important complications}

- Postpartum haemorrhage

- Retention of placenta

- Obstetric shock

- Uterine inversion.

Postpartum haemorrhage is defined as the blood loss of $>500 \mathrm{ml}$ of blood after completion of the third stage of labour. ${ }^{1}$ PPH may occur due to failure of uterus to contract adequately (atonicity), trauma either cervical or vaginal lacerations and tears, uterine rupture, retained placental tissue and maternal bleeding disorders.

Uterine atony is the cause in $50 \%$ cases. With the separation of placenta, the uterine sinuses, which are torn, cannot be compressed effectively due to imperfect contraction and retraction of the musculature. Retained placenta means failure to deliver placenta within 30 minutes using active management of third stage and 60 minutes by physiological management. ${ }^{2}$ The incidence of retained placenta is $2 \%$ at term and markedly increases during preterm. ${ }^{2}$ Retained placenta can be either trapped placenta or adherent placenta. Adherent placenta (placenta accreta spectrum), refers to the range of 
pathologic adherence of the placenta, including placenta accreta, placenta increta, placenta percreta. The incidence of placenta accrete spectrum is increasing due to increasing caesarean section rate.

Puerperal inversion of the uterus is one of the classic haemorrhagic disasters encountered in obstetrics. Unless promptly recognized and managed appropriately, associated bleeding often is massive. Risk factors include alone or in combination are functional placental implantation, uterine atony, cord traction applied before placental separation and abnormally adherent placenta such as with the accrete syndromes.

The objective of the present study was to determine the maternal outcome of complications of third stage of Labour and to determine the risk factors and evaluate the management protocols for these complications.

\section{METHODS}

This is retrospective study of 9000 deliveries (vaginal and caesarean) carried out at tertiary care centre from June 2016 to December 2019, out of which 150 had developed third stage complications. Detailed history and examination findings were noted in order to find out the possible cause of post-partum haemorrhage.

During labour, partograph was maintained to detect prolong latent phase and active phase, to detect arrest and protraction of labour. Active management of third stage of labour (AMTSL) was practiced in all laboring women. It included uterotonic medication (oxytocin-10 unit intramuscular) administered after delivery of baby, late cord clamping (>60 sec of birth) and controlled cord traction until separation and delivery of the placenta. Observation of vitals and bleeding per vaginum was done for 1 hour after delivery. Blood loss was assessed on the basis of measurement from the basins, linens, mops and sponges. In all cases necessary investigations were carried out and patients managed accordingly. The data collected was analysed systemically and observations were compared with other studies.

\section{Inclusion criteria}

- Patients who developed any complications of third stage of labour after vaginal delivery or caesarean section were included.

\section{Exclusion criteria}

- Patients with bleeding due to any other cause (bleeding disorders).

\section{RESULTS}

During study period from June 2016 to December 2019, 9000 women were delivered (vaginal delivery-5400 and caesarean section-3600). Among these 150 (1.66\%) women had various complications during third stage of labour.

Out of the women having complications, $48.67 \%$ were between $18-24$ years, $24.67 \%$ were between $25-28$ years, $26 \%$ were between $29-35$ years, $0.66 \%$ were above 35 years of age.

Out of the woman having complication, $63.34 \%$ were primigravida, $29.33 \%$ were multigravida and $7.33 \%$ were grand multipara.

Out of woman having complication, $33.33 \%$ patients had significant past obstetric history of interventional procedures that deal with the uterine cavity as a whole that increase the chances of placenta previa and placenta accreta spectrum. ${ }^{1}$

Anemia, malpresentation, adherent placenta, PIH were the comorbid factor seen in women having third stage complication (Figure 1).

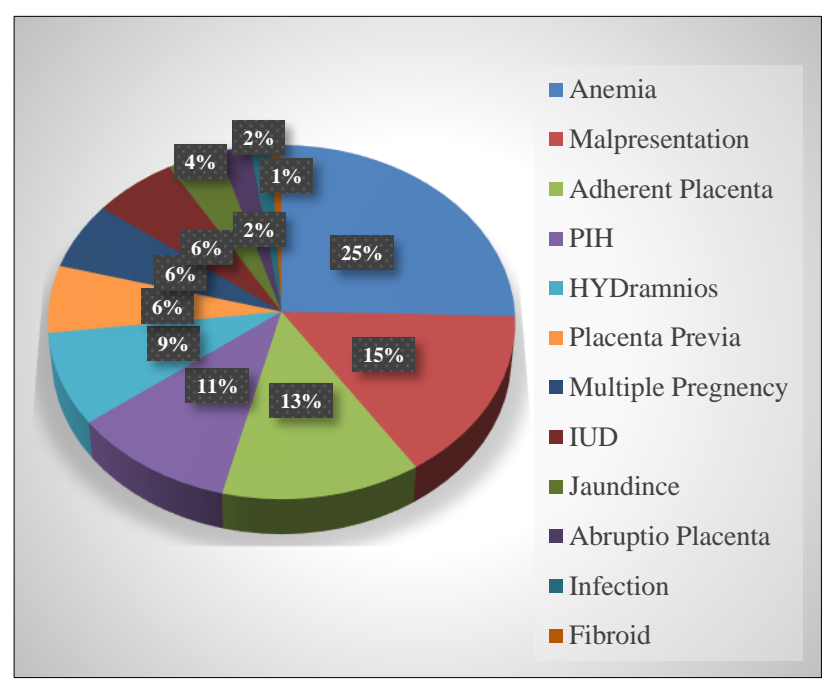

Figure 1: Co-morbid condition and third stage complications.

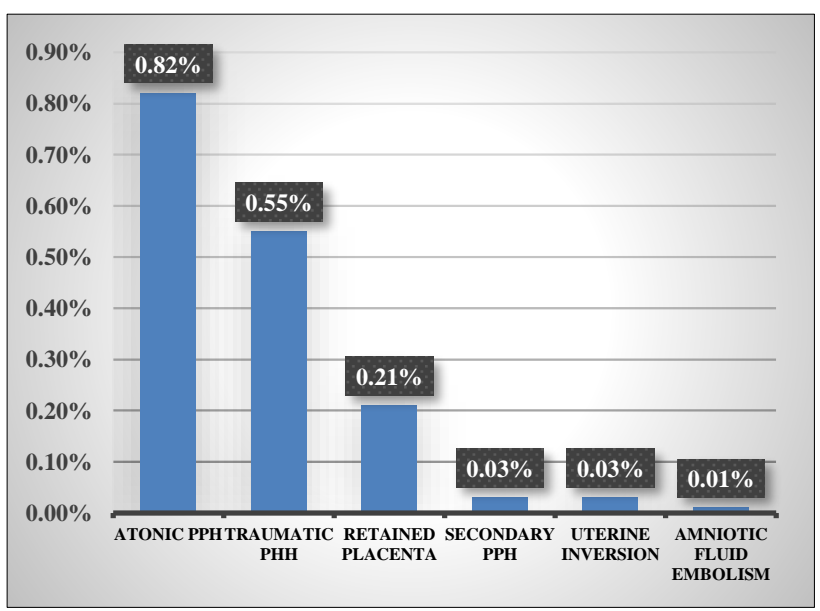

Figure 2: Different type of third stage complications. 
In present study, out of 9000, 5400 women had undergone vaginal delivery out of which $96(1.77 \%)$ had developed third stage complications. Out of 3600 women who had undergone caesarean section, 54 (1.5\%) had developed third stage complications.

Complication which were observed to occur during third stage of labour were shown in Figure 2. In the present study, $0.82 \%$ had atonic PPH and $0.55 \%$ had traumatic
PPH, $0.21 \%$ had retained placenta, $0.03 \%$ had secondary $\mathrm{PPH}, 0.03 \%$ had uterine inversion and $0.01 \%$ had amniotic fluid embolism (Figure 2).

Risk factors for atonic PPH are induced labour (26.39\%), $\mathrm{PIH} /$ pre-eclampsia/eclampsia (16.67\%), multiparity (15.28\%), hydramnios (15.28\%), multiple pregnancy, placenta previa $(6.94 \%)$, prolonged labour $(5.56 \%)$, infection $(2.7 \%)$, abruptio placenta (1.39\%) (Table 1).

Table 1: Risk factors of atonic PPH.

\begin{tabular}{|lll|}
\hline Risk factors & No. of patients $\mathbf{n = 7 4}(\%)$ & $\begin{array}{l}\text { Over all contributing percentage of } \\
\text { complications } \mathbf{n}=\mathbf{9 0 0 0}(\%)\end{array}$ \\
\hline Induced labour & $19(26.39 \%)$ & $19(0.21 \%)$ \\
\hline PIH/pre-eclampsia/eclampsia & $12(16.67 \%)$ & $12(0.13 \%)$ \\
\hline Multiparity & $11(15.28 \%)$ & $11(0.12 \%)$ \\
\hline Hydramnios & $11(15.28 \%)$ & $11(0.12 \%)$ \\
\hline Multiple pregnancy & $7(9.72 \%)$ & $7(0.07 \%)$ \\
\hline Placenta previa & $5(6.94 \%)$ & $5(0.05 \%)$ \\
\hline Prolonged labour & $4(5.56 \%)$ & $4(0.04 \%)$ \\
\hline Infection & $2(2.76 \%)$ & $2(0.02 \%)$ \\
\hline Abruptio placenta & $1(1.39 \%)$ & $1(0.01 \%)$ \\
\hline
\end{tabular}

Table 2: Traumatic causes of PPH.

\begin{tabular}{|lll|}
\hline Site of injury & No. of patients $\mathbf{n = 5 0}(\%)$ & $\begin{array}{l}\text { Over All contributing percentage of } \\
\text { complications } \mathbf{n}=\mathbf{9 0 0 0}(\%)\end{array}$ \\
\hline Cervical tear & $16(32 \%)$ & $16(0.17 \%)$ \\
\hline Vaginal tear & $11(22 \%)$ & $11(0.12 \%)$ \\
\hline Rupture uterus & $10(20 \%)$ & $10(0.11 \%)$ \\
\hline Lower uterine segment tear & $4(8 \%)$ & $4(0.04 \%)$ \\
\hline Episiotomy wound hematoma & $3(6 \%)$ & $3(0.03 \%)$ \\
\hline Complete perineal tear & $2(4 \%)$ & $2(0.02 \%)$ \\
\hline Cervical + vaginal tear & $2(4 \%)$ & $2(0.02 \%)$ \\
\hline Perineal + vaginal tear & $1(2 \%)$ & $1(0.01 \%)$ \\
\hline Perineal tear & $1(2 \%)$ & $1(0.01 \%)$ \\
\hline
\end{tabular}

Out of patients having atonic PPH, 61\% had undergone caesarean delivery and $39 \%$ had undergone vaginal delivery.

Out of patient who developed traumatic PPH, 32\% had cervical tear, $22 \%$ had vaginal tear, $20 \%$ had rupture uterus (Table 2).

Out of $49.33 \%$ case of atonic PPH, $18 \%$ case were responded to medical treatment, $8 \%$ responded to medical + intrauterine packing, $8 \%$ medical $+\mathrm{B} / \mathrm{L}$ uterine artery ligation. Out of $33.33 \%$ case of traumatic PPH, $11.33 \%$ case were managed by complete perineal tear repair, $10.67 \%$ case were managed by only cervical tear repair. Out of $12.67 \%$ case of retained placenta, subtotal obstetric hysterectomy was performed in $6 \%$ case, total obstetric hysterectomy was performed in $2 \%$ cases (Table $3)$.

Surgical interference was required in $79 \%$ cases. Uterine artery ligation was used in $16 \%$ case to control PPH out of which $7.33 \%$ cases needed further steps like ovarian artery ligation, compression suture or internal iliac ligation to control $\mathrm{PPH}$.

In present study, out of the women having complications, a total of $84 \%$ patients needed PCV transfusion, $42.67 \%$ needed FFP transfusion, $34.67 \%$ needed PRC transfusion and $31.33 \%$ CRYO transfusion.

In $15.33 \%$ cases there was no need of transfusion of blood or blood products. 


\section{DISCUSSION}

In present study, out of 9000 women, 150 women had various complication during third stage of labour. They were evaluated for the spectrum of complications and the associated conditions.
Present study shows that the maximum occurrence of complications of the third stage is in the age group 18-28 years. Kaul $\mathrm{V}$ et al reported that mean age of occurrence of these complications were age of 23.3 Above study shows that occurrence of these complications is more in period of maximum fertility.

Table 3: Management of third stage complications.

\begin{tabular}{|lll|}
\hline Methods & Percentage \\
\hline Atonic post-partum hemorrhage & $\mathrm{N}=74(\%)$ & $\mathrm{N}=9000(\%)$ \\
\hline Only medical & $27(18 \%)$ & $27(0.3 \%)$ \\
\hline Medical + intrauterine packing & $12(8 \%)$ & $12(0.13 \%)$ \\
\hline Medical + B/L uterine artery ligation & $12(8 \%)$ & $12(0.13 \%)$ \\
\hline Medical + B/L uterine artery ligation + CHO sutures & $7(4.67 \%)$ & $7(0.07 \%)$ \\
\hline Medical + B/L uterine artery ligation +ovarian ligation + CHO sutures & $2(1.33 \%)$ & $2(0.02 \%)$ \\
\hline Medical + B/L uterine artery + ovarian ligation + B/L internal iliac ligation & $1(0.67 \%)$ & $1(0.01 \%)$ \\
\hline Subtotal obstetric hysterectomy & $3(2 \%)$ & $3(0.03 \%)$ \\
\hline Subtotal obstetric hysterectomy + internal iliac ligation & $1(0.67 \%)$ & $1(0.01 \%)$ \\
\hline Total obstetric hysterectomy & $7(4.67 \%)$ & $7(0.07 \%)$ \\
\hline Total obstetric hysterectomy + internal iliac ligation & $2(1.33 \%)$ & $2(0.02 \%)$ \\
\hline Traumatic post-partum hemorrhage & $\mathrm{N}=40(\%)$ & $\mathrm{N}=9000(\%)$ \\
\hline Cervical tear repair & $16(10.67 \%)$ & $16(0.17 \%)$ \\
\hline Vaginal + perineal + complete perineal tear repair & $17(11.33 \%)$ & $17(0.18 \%)$ \\
\hline Lower segment tear repair & $4(2.67 \%)$ & $4(0.04 \%)$ \\
\hline Episiotomy hematoma drainage & $3(2 \%)$ & $3(0.03 \%)$ \\
\hline Retained placenta & $\mathrm{N}=19(\%)$ & $\mathrm{N}=9000(\%)$ \\
\hline Only medical - placenta left in situ after delivery (methotraate) & $1(0.67 \%)$ & $1(0.01 \%)$ \\
\hline B/L uterine artery ligation (focal adherent placenta) & $1(0.67 \%)$ & $1(0.01 \%)$ \\
\hline B/L uterine artery ligation + transverse compression sutures (focal adherent placenta) & $1(0.67 \%)$ & $1(0.01 \%)$ \\
\hline Manual removal of placenta (3 after vaginal delivery and 1 during LSCS) & $4(2.67 \%)$ & $4(0.04 \%)$ \\
\hline Subtotal obstetric hysterectomy (undilated uneffaced cervix left) & $9(6 \%)$ & $9(0.09 \%)$ \\
\hline Total obstetric hysterectomy & $3(2 \%)$ & $3(0.03 \%)$ \\
\hline Rupture uterus & $\mathrm{N}=10(\%)$ & $\mathrm{N}=9000(\%)$ \\
\hline Rupture repair & $3(2 \%)$ & $3(0.03 \%)$ \\
\hline Subtotal obstetric hysterectomy & $1(0.67 \%)$ & $1(0.01 \%)$ \\
\hline Subtotal obstetric hysterectomy + B/L internal iliac ligation & $1(0.67 \%)$ & $1(0.01 \%)$ \\
\hline Total obstetric hysterectomy & $2(1.33 \%)$ & $2(0.02 \%)$ \\
\hline Total obstetric hysterectomy + B/L internal iliac ligation & $3(2 \%)$ & $3(0.03 \%)$ \\
\hline Secondary PPH & $\mathrm{N}=3(\%)$ & $\mathrm{N}=9000(\%)$ \\
\hline Medical & $2(1.33 \%)$ & $2(0.02 \%)$ \\
\hline Dilatation and evacuation & $1(0.67 \%)$ & $1(0.01 \%)$ \\
\hline Uterine inversion & $\mathrm{N}=3(\%)$ & $\mathrm{N}=9000(\%)$ \\
\hline Manual reposition & $2(1.33 \%)$ & $2(0.02 \%)$ \\
\hline Haultain's repair & $1(0.67 \%)$ & $1(0.01 \%)$ \\
\hline
\end{tabular}

Present study shows high incidence of third stage complications in primipara $(63.34 \%)$ which is similar to Kaul V et al and L Gilbert et al studies (60\%)., Primiparas are more prone to prolonged labour, uterine inertia, and operative interference all of which predispose to PPH. Babinszki et al reported that among postpartum maternal complications, the incidence of haemorrhage increased significantly in multiparous and grand multiparous patients. ${ }^{5}$ In grand multipara size of the baby increases, incidence of malpresentation is high, both uterine and abdominal wall lack a good muscular tone, incidence of antepartum haemorrhage is high. Moreover, as a result of repeated child birth, poverty, malnutrition, overwork, and chronic iron deficiency anemia these 
women are in poor condition to withstand even a slight amount of blood loss. ${ }^{5}$

In present study uterine atony is the most common type of third stage complication accounting for $49.33 \%$ of cases. Traumatic causes of PPH comprises of $33.33 \%$ cases out of which $0.11 \%$ were cases of ruptured uterus and $0.44 \%$ traumatic PPH from other causes. Thus, postpartum haemorrhage is the most common third stage complication comprising of $82.67 \%$ of atonic and traumatic cases. Duhan L et al reported $87.5 \%$ of third stage complications as postpartum haemorrhage. ${ }^{6}$ Thus postpartum hemorrhages remains the most common third stage complication.

In present study about $18 \%$ patients with atonic PPH, $1.33 \%$ patients with secondary $\mathrm{PPH}, 0.67 \%$ patients with retained placenta responded to medical management. FIGO consensus guidelines on placenta accrete spectrum disorders: The use of methotrexate is not recommended until further evidence is available on its efficacy and safety. ${ }^{7}$ Prendiville $\mathrm{W}$ et al stated that routine administration of oxytocin does have an effect on rate of PPH reducing it about $40 \%{ }^{8}$ As per the WHO Recommendations for the prevention of postpartum haemorrhage, the use of uterotonics (10 U IV or IM) during third stage of labour is recommended for all births. ${ }^{9}$ Merrikay A et al, study states that haemorrhage was successfully controlled immediately after the administration of hemabate sterile solution (15 methyl PGF2 alfa) in $87.8 \%$ cases. ${ }^{10}$ Surgical interference was required in $80 \%$ cases. Uterine artery ligation was used in $24(16 \%)$ cases to control PPH out of which $11(7.33 \%)$ cases needed further steps like ovarian artery ligation, compression sutures or internal iliac ligation to control PPH. Thus, uterine artery ligation was $54.2 \%$ successful in control of postpartum haemorrhage. SJ Kore study on stepwise devascularization on 23 patients achieved success in $95.7 \%$ cases. ${ }^{11}$ In present study internal iliac Ligation was done in 8 cases in which 7 times the internal iliac ligation was done along with total/subtotal hysterectomy. Only in one case haemorrhage was controlled by ligation alone. Nandanwar YS conducted internal iliac ligation for the control of PPH in 8 cases and was successful. ${ }^{12}$

Transfusion of blood and blood products is necessary when the extent of blood loss is significant and ongoing, particularly if vital signs are unstable. Also, in patients with anaemia it is necessary to give transfusion of PCV. Better availability of facilities, skilled obstetrician, anesthetists, blood transfusion services, ICU setup and above all team work and spirit to work for patients can lead to successful management of PPH.

\section{CONCLUSION}

Third stage complications are potentially life threatening for both vaginal and caesarean deliveries.
As obstetric care improves, the incidence of third stage complications decreases and maternal deaths from it drastically reduce. A targeted approach has to made to combat these complications and these may be in form of anaemia detection and correction, dietary supplementation, institutional deliveries, avoidance of prolonged labour, training of birth attendants, increasing the skills for those attending deliveries is considered effective, active management of third stage of labour, emergency care, ask for help, training for correct use of uterotonics, accurate diagnosis of cause of bleeding, adequate and prompt restoration of circulatory volume, any form of operative procedure should be performed timely.

Since last decade, conservative surgical procedures have been successfully used in various circumstances and forms. A conservative surgical approach not only controls these complications but also preserves women's reproductive functions and consequences.

Thus, early anticipation and early intervention with proper planning is required to reduce the maternal morbidity and mortality in third stage complication.

To conclude prevention is better than cure.

\section{ACKNOWLEDGMENTS}

Authors would like to thank to all faculties colleague, post graduate residents and labour room staff for their support.

\section{Funding: No funding sources \\ Conflict of interest: None declared \\ Ethical approval: The study was approved by the Institutional Ethics Committee}

\section{REFERENCES}

1. Whitridge J, Williams. Obstetrical haemorrhage. In: Cunningham, Leveno Bloo, Spong, Dashe, Hoffman, Casey, Sheffield. Williams Obstetrics $25^{\text {th }}$ ed. New York, NY: McGraw-Hill; 2019:755-795.

2. NSW HEALTH guideline for maternity-prevention, early recognition and management of postpartum hemorrhage; 2010.

3. Kaul V, Bagga R, Jain V, Gopalan S. The impact of primary postpartum hemorrhage in" nearmiss" morbidity and mortality in a tertiary care hospital in north India. Indian J Med Sci. 2006;60(6):233-40.

4. Gilbert L, Porter W, Brown VA. Postpartum haemorrhage: a continuing problem. Int J Obstet Gynaecol. 1987;94(1):67-71.

5. Babinszki A, Kerenyi T, Torok O, Grazi V, Lapinski RH, Berkowitz RL. Perinatal outcome in grand and great-grand multiparity: effects of parity on obstetric risk factors. Am J Obstet Gynecol. 1999;181(3):66974. 
6. Duhan L, Nanda S, Sirohiwal D, Dahiya P, Singhal $\mathrm{S}$, Vandana V. A retrospective study of maternal and perinatal outcome in patients of postpartum haemorrhage in a tertiary care hospital. Int J Reprod Contracept Obstet Gynecol. 2016;5(6):1897-901.

7. Sentilhes L, Kayem G, Chandraharan E, PalaciosJaraquemada J, Jauniaux E, FIGO placenta accreta diagnosis and management expert consensus panel. FIGO consensus guidelines on placenta accreta spectrum disorders: conservative management. Int $\mathrm{J}$ Obstet Gynecol. 2018;140:291-8.

8. Prendiville W, Elbourne D, Chalmers I. The effects of routine oxytocic administration in the management of the third stage of labour: an overview of the evidence from controlled trials. Int $\mathbf{J}$ Obstet Gynaecol. 1988;95(1):3-16.

9. WHO. Recommendations for the prevention and treatment of postpartum hemorrhage. 2012. Available at: http://apps.who.int/iris/bitstream/handle /10665/75411/9789241548502_eng.pdf;jsessionid=8
66F8B2F71B917B9A9CE922D484CDA9B?sequenc $\mathrm{e}=1$. Assessed on $12^{\text {th }}$ January 2020.

10. Olum MA, Mariano, Controlling refractory atonic postpartum haemorrhage with hemabate sterile solution. Am J Obst Gynecol. 1990;162(1):205-8.

11. Kore SJ, Parikh M, Lakhotia S, Bapai A, Kulkarni V, Chopde-Shah B, et al. Stepwise uterine devascularisation: an alternative to hysterectomy in non-traumatic, intractable postpartum hemmorrhage. Bombay Hosp J. 2007;26:3-4

12. Nandanwar YS, Jhalam L, Mayadeo N, Guttal DR. Ligation of internal iliac arteries for control of pelvic haemorrhage. J Postgrad Med. 1993;39(4):194.

Cite this article as: Rangholiya KK, Agrawal SP, Shah SR, Dodiya H. Evaluation of complication during third stage of labour at tertiary care center. Int J Reprod Contracept Obstet Gynecol 2020;9:244651. 